\title{
Natural Science Value of Linguistics in Historical Research
}

\author{
Antipenko Leonid Grigoryevich \\ Institute of Philosophy, Department of the Philosophy of Natural Sciences, Moscow, Russian Federation
}

\section{Email address:}

chistrod@yandex.ru

\section{To cite this article:}

Antipenko Leonid Grigoryevich. Natural Science Value of Linguistics in Historical Research. English Language, Literature \& Culture. Vol. 4, No. 4, 2019, pp. 93-98. doi: 10.11648/j.ellc.20190404.12

Received: July 18, 2019; Accepted: August 26, 2019; Published: December 24, 2019

\begin{abstract}
Martin Heidegger divided the researchers engaged in questions of history into two categories - historians and historiographers. Historiographers are immersed in the study of language texts and other artifacts left over from the past. Historians go further. They seek to immerse themselves in the flow of historical time and, in addition to the study of linguistic written texts, to present the sounding speech of the past human generations. To present speech is to have some experience in this regard. This experience is taken, according to Heidegger, from poetic and musical creativity. From this it is concluded that the historical events or even entire epochs are resonated, just as the harmonic consonance between the musical phrases of a symphony or sonata performed in time is realized. These phenomena are discussed in this article. To this it must be added that the results obtained in the article are not the fruits of musical-poetic intuition alone. They undergo rigorous testing in accordance with Heidegger's developed dialectic technique, based on the logical operation restored by him in philosophy and called privation.
\end{abstract}

Keywords: Language, Speech, Historical Time, History and Historiography

\section{Introduction: Musical Compositional Approach to the Problematic}

G. V. Sviridov argued that the artist is called to serve, to the best of his power, the disclosure of Truth, and the Truth can be contained in the synthesis of Music and the Word. Taking into account this judgment of the great composer, we would like to present a view of history through the prism of musical and verbal logos, melos and poetry. We quote in this context one passage by K. Lévi-Strauss. Imagine, he wrote, alien archeologists who appeared on Earth after mankind disappeared from it and excavated at the site of one of our libraries. These archaeologists completely unknown to our writing, but they are trying to decipher it. To do this, they need to pre-set what we write from left to right and from top to bottom. But even after this discovery, part of the books cannot be decrypted. This will be a kind of orchestral scores stored in the music department. Scientists are trying to read musical lines one after another, starting at the top of the page; over time, they will notice that some groups of notes are repeated partially or completely at certain intervals, and some melodic phrases that are at a distance from each other are similar to each other. "In that case," Lévi-Strauss writes, "they may come to mind that these melodic phrases should be viewed not sequentially, but as parts of a whole, and cover them entirely. Then they will discover the principle of what we call harmony. An orchestral score makes sense only when it is read diachronic along a single axis (page by page, from left to right) and along with it on the other axis simultaneously from top to bottom" [1].

Musical Symphony (Sonata, Overture) unfolds in the performance over time, but time in this case appears in different ways depending on whether it judges the external observer or the man, experiencing its symphonic content. Something similar happens in the stream of historical time, when we dive into it and begin to realize that the language of a family, tribe, people serves to a certain extent as an analogue of the sound of a musical ensemble.

This awareness comes along with the understanding that the language has two functions. One of them consists in communication of people as regards their economic life, without which it is inconceivable, say, a material exchange in the human community. The other is supra - material, rhythmic, that which is expressed in a song, a hymn, an appeal to that which rises above utilitarian-economic needs. This live speech transmitted from generation to generation over the course of historical time makes it possible to catch a 
long-range connection (correlation) between historical events separated in time, that, in particular, reveals itself, in the words of M. Heidegger, as "a roll-call of the source and the goal" [2].

In general, we are talking about the existence and manifestation of the phenomenon of long-range instantaneous communication between individual layers of historical-temporal reality, which O. Spengler called historical gestalts (from him: Die Gestalt - form, type, image) [3].

Heidegger in place of the word gestalt puts the term era and speaks about the existence of a mutual roll-call of eras [2]. Language and speech are the means of expression of this interchange. In general, in order to conclude that there is a long-range action in historical time, we need to combine linguistics with the main provisions of Heidegger's fundamental ontology.

As for the significance of the results of this study on the whole, it consists in the following. Here is an example of the relationship between linguistics and history, which is revealed by the method developed in Heidegger's fundamental ontology. This method, in fact, is dialectical, but it is fundamentally different from Hegel's dialectic. Its main difference is in the logical operation of negation, which is called privation. About here the distinction is made between speech and language, between historians and historiographers.

My previous research in this area is marked by the article «Yestestvennonauchnaya otsenka postmodernistskogo podchoda $\mathrm{k}$ lingvistike i litreraturnomu tvorchestvu [Natural Science Assessment of Post-modernist Approach to Linguistics and Literary Creativity] [12].

\section{Language and History in the Context of M. Heidegger's Fundamental Ontology}

Subjecting a critical review of the Western European metaphysics in all its variants over the course of historical development, beginning with antiquity, Heidegger showed that philosophical understanding of the reality that surrounds us requires an answer to such questions as why a conversation about the real is accompanied by a judgment about nothing? Why is there being when nothing could be? Why is nothing as attached to the presence of being? In search of an answer to these questions, Heidegger divided the reality into two levels: ontic and ontological. At the ontic level, he placed things (Seiende), and identified the ontological level with what he called Being (with a capital letter), in German Sein or (later) Seyn. The link between these two levels is the just-being, Dasein. Dasein took the place of the subject in the cognitive activity of the former metaphysics, but so that it was elevated to the level of Being (in any case, in the true mode of its existence).

If we now ask what it means to be on the ontological level then it will be answered: it means to be present at the level of mutual belonging of Being and time. In the article "Time and Being." Heidegger writes: "What determines both, time and Being, in their own essence, i.e. in their mutual affiliations, we call: the event" [2]. But what is an event? The author points out, first of all, how in this case one should not understand the event. "We can no longer imagine what is called the name "event" by the guiding thread of a common dictionary meaning; for by them "event" is understood in the sense of incident - not from the fact that it comes true..." [2]. It comes true does not just happen, but is retiring, ends. But can time run out? Time, like Being, has no end, but knows the transition from one phase of the flow, the flow in one direction, to another phase, to the flow in the opposite direction. And the transition from one phase to another takes place out of time. This lack of time, the lack of Being, is the very Nothing that accompanies Being that "permeates" it.

To understand the logic of the relationship of Being and Nothing, Heidegger refers to a logical operation, which was first used by Plato in the Sophist and called privation. If we, Heidegger argues, we deny something so that we do not just exclude, but rather fix in the sense of shortage, then such denial is called privation [3]. He further reports that it took the Greek philosophers two hundred years to arrive at the idea of privation. "Only Plato in the dialogue Sophist discovered and considered denial as privation. This occurs in connection with the discretion of the fact that not every nonbeing simply is not there, which, on the contrary, is such a non-being that is in a certain way" [3].

In Russian, the event is transmitted sometimes as coexistence, i.e. as the contact of one being with another. But this contact is apparently not a coincidence. one with the other, but rather the juxtaposition of opposites. In Heidegger's fundamental ontology contact opposites occur so that the transition from one extreme to the other does not take time. In addition, the Heidegger's temporality of Being is also distinguished by the fact that it covers three dimensions of time: present, past and future. In this case, metaphysical attempts to comprehend time from the present, from what appears as Now, fall away. When we have, Heidegger writes, to characterize time on the basis of the present, we, of course, understand the present as Now, unlike the now-not-now past and not-now of the future. This is a metaphysical tradition. Thus Aristotle says that what from time there is (or present), it is every Now. The past and the future are $\mu \eta$ ő $\tau \mathrm{l}$ : but Nothing exists, although it is not just Nichtigkeit and a such presence that something is missing, what is denoted by the lack of "have not" and "not yet." "So seen, time turns out to be a series of consecutive Now, of which each, barely named, immediately disappears into "that's what" and already persecuted the coming "right now" [2]. But such an idea of time arises when it is immersed in the calculation, for example, is counted on the watch face. In a mechanically leveled time, his own being is lost.

And it is restored when time is given an existential meaning. This value we find, according to Heidegger, then, when we turn to just-being (Dasein), to man. Man is finite, mortal, but each has his own moment of death, it is 
impossible to arrange in time the departure of each person from life. At the same time, for each person the horizon of his life is indicated. Therefore, in making judgments about time, we must reckon with the presence of this horizon. The first book by Heidegger, Being and Time, published in 1927 [4], is devoted to the analysis of all such judgments and the corresponding conclusions from them.

Heidegger is not taken directly to judge what is beyond the horizon of a particular person, but he argues that this truth, like any other, is revealed in time as not-hidden (aletheia). And truth-aletheia is expressed in language. However, language is not only a means of expressing truth, it is a logically ordered tale of Being, which is denoted by one word: logos. The Heidegger's article "Word" contains the following statement: "The oldest word for meaningful power of the word, for speech, is called sóyos: Tale, which, showing gives beings (Seiende) appear in their it is.

The same word $\Delta$ óyos as a word for tale is at the same time a word for being, i.e. for the presence of the present. A word and a being, a word and a thing, by some kind of slightly revealing, hardly thought out and inconceivable image, mutually belong to each other" [2].

Further, it turns out that this inconceivable affiliation is due to the fact that the poetic structure of speech is added to the logos, the logical structure of the vocabulary, and with it the melos. Heidegger, explicitly or implicitly, draws an analogy between the long-range correlation between separate epochs in historical time and musical harmony between separate fragments in a symphony developed in time. At the same time, he makes the reservation that the sequence of epochs, which overlap with each other, is not accidental, but "cannot be calculated as inevitable" [2, p. 396]. There remains a probabilistic statistical assessment of such coincidences.

\section{Speech, Language, History and Historiography}

Heidegger subdivides researchers engaged in historical issues into two categories -historians and historiographers. Historiographers are content to study texts and other artifacts left over from the past. Historians, on the other hand, are capable of adding to what historiographers do, to enter the flow of historical time and make their judgments based on this experience. "All my "historiographic" (historisch) lectures and "interpretations", writes Heidegger in his diary, "are historical reflections (geschichtliche Besinnungen), not historiographic reflections (historische Betrachtungen)" [5]. Historical reflection, the diary informs, is the overcoming of historiography. "Inadequate, because the external attitude towards history, in the form it developed the axis in today's historiography that led to historicism, cannot be overcome by fleeing from history, but only by entering passing of history (das Geschichten der Geschichte) [5]. Historiography, with its external approach to the historical process, is, according to Heidegger, permanent, and also unavoidable, distortion and destruction (Verschüttung) of history [5].

Appeal to language, according to Heidegger, allows you to eliminate this distortion and destruction. In Heidegger's argumentation about language, "there is a purified repetition of the question of Being" [6]. In order to go further along the path of this questioning, the essence of the language is supposed like a tale. In the tail (Saga) language is silent. He needs human speaking. Thought of Heidegger moves from language to speech. The article "The Path to Language" contains the following statement: "The delegation of mortals to tales releases the human being to the demands where a person is required to bring a silent tale to the sound of speech" [2]. A language that is not separable from speech is that which allows one to penetrate history. After all, there is no natural language of this kind, that it is the language of a non-historical, naturally existing human nature. "Every language is historical, even where a person has not joined historiography in the modern European sense" [2].

Heidegger's ideas of great difficulty in reading and understanding are presented in a more accessible form by a number of other thinkers, to whose ranks the Russians belong. So V. V. Kolesov in the book «Ancient Russia and the Legacy in a Word» characterizes the same two types of historians by means of the following judgments. The historian of the first type finds it difficult to penetrate into the feeling and thought of the ancestors, it seems to him that the actors act in silence, fight, reconcile, but neither they themselves will say, nor the chronicler will add from himself what they are fighting for, and therefore reconcile; " in the city, in the prince's court, nothing is heard, everything is quiet; everyone sits shut and thinks about himself; the doors are opened, people come on the scene, they do something, but they do it silently, so says S. Solovyov, an expert on ancient Russian sources" [7]. Such an impression, Kolesov writes, to the linguist historian seems strange, because the chronicles are replete with replicas of heroes, the noise of the crowd, the breath of time; we constantly hear the voices of the past, we can even distinguish the intonation of speech and the mood with which words are pronounced. "The words themselves are also important, individually and collectively, always so significant in the general flow of events, actions, and speeches. They can also tell a lot about the meaning of distant events ... " [7]

But the question is how can we hear these speeches of our ancestors? The living language of this or that people has, as already mentioned, a syntactic-melodic and harmonic structure. In its development, it retains these qualities to one degree or another. Changes are more subject to vocabulary, and melody is preserved longer. We find its preservation in Russian literature, especially if we take for example the "Word about the regiment of Igor". We also learn that the language in which the inhabitants of St. Troy and all the Pelasgian tribes spoke, is a proto-language of the Slavs. About this we were told in their studies, the Italian historian scientist, presbyter, philologist, Slavic and Etruscology Sebastiyano Chyampi (Sebastiano Ciampi (1769 - 1847) and the outstanding Russian historian, scientist, archaeologist, 
numismatist A. D. Chertkov (1789-1858) [8]. The affinity of the Etruscan language with the Slavic languages is proved, and the Etruscans (raseny, roseny) are part of the TroyanPelasgow survivors of the Trojan War who emigrated to Italy. Traces of their language remained in the language of the Greeks, a sign of which is the presence of the letter digamma in the oldest version of the Greek alphabet.

Now let us return to the question of harmony in music and in speech and the long-range correlation between historical eras. Musical and compositional art can not be reduced to a cause - effect relationship (algebra) between chords and notes. The musical logo, or melos, is based on a semantic connection between them. The same applies to the verbalpoetic logo. The appeal to the verbal-poetic logo in the analysis of historical events makes it possible to get rid of the so-called narrative in their description. The concept of the narrative, invented by P. Ricoeur, sets the task of ridding the presentation of the real story from the lacunae that are formed when trying to close the course of historical events into the causal framework, fully integrate them into a chain of causation. But how justified is the causal view of history? We can judge this by the argumentation of one of her strong supporters. He is Count Leo Tolstoy and the second (1828 1910).

As is well known Tolstoy is the author of the novel War and Peace. In the epilogue of this novel, he shared with the reader thoughts about how he assesses the course of historical events in general and those events that he, as an artist, captured in the work he created. So the subject of history, he wrote as the author of "War and Peace" is the life of nations and of humanity. Directly catch and embrace the word - to describe the life not only of humanity, but of one people,-it seems impossible. All ancient historians used the same technique in order to describe and grasp the seemingly elusive life of the people. They described the activities of individuals who rule the people; and this activity expressed for them the activity of the whole people. To questions about how individual people forced the people to act according to their own will and how the will of these people was controlled, the ancients answered: "to the first question, recognition of the will of the deity who subordinated the peoples to the will of one chosen person; and the second question - recognition of the same deity, who directed this will of the chosen to the intended purpose" [9]. In a word: "For the ancients, these questions were resolved by faith in the direct participation of the deity in human affairs" [9].

The new story, the author points out, rejected both of these provisions. But what, in his opinion, should be put in return? It is necessary to explain how, against the background of scientific necessity, the idea of free will arises. Where does it come from? The answer is: what we know in history, we call the laws of necessity, just as it is done in the experimental sciences. And that which is unknown is called freedom. "Freedom for history is an expression of the unknown remainder of what we know about the laws of human life" [9]. Consequently, freedom, according to Tolstoy, is an aberration of the historical form of consciousness of people, arising from incomplete knowledge of the subject. And in order to eliminate this aberration, it is necessary to eliminate the reasons causing it from the human imagination. The reasons he calls manifestations of free will, volition. Nothing will be left of free will when the laws of continuous movement are established. "The search for these laws," says Tolstoy, "has long been started, and those new methods of thinking that history has to assimilate for themselves are being worked out simultaneously with self-destruction, to which, crushing and crushing the causes of phenomena, goes the old history" [9].

He believes that all human sciences followed this path. The sample is mathematics. Having come to the infinitely small, this most exact of science, according to Tolstoy, leaves the crushing process and embarks on a new process of summing unknown, infinitely small quantities. "Departing from the concept of reason, mathematics finds a law, that is, properties common to all unknown infinitesimal elements" [9].

Tolstoy correctly noted that the ancient thinkers, trying to explain the course of historical events, could not help but notice that they were far from always determined by causeeffect relationships, and therefore turned their attention to the gods. However, wanting to get rid of the appeal to the deity, he, in fact, relies on the concept of Laplace determinism. And this is the extreme case in the approach to the construction of historical science, which presents mechanism. And it should be noted that in the field of social and human sciences the mechanistic world outlook was sharply criticized by Russian thinkers, contemporaries of Tolstoy, who were busy searching for spiritual truth in its connection with the ideas of freedom and necessity. Among them is our distinguished compatriot A. S. Khomyakov (1804-1856). Human thought, he wrote, is connected with the strict laws of logical necessity from the action of life and its dependence on the nature of the outside. "It seems reasonable that only develops in the linking of causes and effects. The beginningless and self-existing will, intangible for the inquiring mind, receives the whole character of arbitrary conjecture and, in comparison with certain concepts derived from life experience, falls on the degree of dark and doubtful instinct" [10]. And what is the result? Yes, according to Khomyakov, science has so far failed to "bring the logical development further to the self-negation of necessity, which returns freedom to thought, but freedom itself is still a stigma of denial and does not represent the creative and all-powerful will" [10]. Therefore, if freedom and defends their right to volition, there is no other way than in the "images and symbols of religious" [10].

In Heidegger's fundamental ontology, the "dark and dubious instinct" disappears, as well as the need to resort, in order to present freedom, to religious images and symbols. All this is replaced by the properties of historical time, each dimension of which present, past and future -takes place in unity, i.e. in the length that Heidegger calls the fourth dimension [2]. The present is subject to long-range influence from both the past and the future. The roll- call of one or 
another epoch, enclosed by time, cannot be calculated as inevitable. Their correlation can be assessed only in the language of mathematical expectation. Consequently, there remains a place of free will.

\section{Conclusion}

Our speech consists of separate words; words are divided into sounds, which in written language are denoted by alphabetic characters. Letters perform about the same role in speech as notes in a piece of music. But a piece of music leads to a clear understanding of the fact that both speech and music consist of opposite elements "yes" and "no". In speech, this becomes quite noticeable when verbal-poetic logos are considered. In the melos-clearly: raising and lowering the tonality, on which the chords are built. In both cases, it may be some arbitrariness in relation to the time duration of the parts into which the divided speech and music phrase. However, this arbitrariness is limited by the laws of musical composition and grammatical and phonetic expressiveness.

Let us now imagine that we are in direct contact with the temporary verse that also consists of parts with the opposites 'yes' and 'no', but these parts are quantized and unchangeable, just as unchanging quantum (minimum value) operations in quantum physics. At the same time, the task is to learn how to manage the course of time, like the composer controls the musical symphony or sonata. How can this task be accomplished -a time management task? The only possibility to solve it to some the least is to enter statisticallyprobabilistic assessment of fall of "yes" and "no" and learn to control (manage) the probability distribution. To this conclusion we have summed up their research on the problem of mastering the time of the great Russian thinker Valerian Nikolayevich Muravyov (1885-1932).

By the way, this problem was formulated by him, as far as we know, for the first time. Moreover, in his years Muravyov could not be familiar with the laws of quantum physics, in particular, with the process of the reverse flow of time, but, nevertheless, he intuitively guessed that such a process existed. Many researchers, and in particular, followers of Dalcroze, he wrote, drew attention to the importance of rhythm for the perception of time. (Dalcroze Jacques Emile (1865-1951) - Swiss composer and teacher who developed the system of musical and rhythmic education. Institutes and schools by the method of Dalcroze were common in many countries). However, no practical conclusions were drawn from this and "here we have the same halt as representatives of theories of. labor organization, when they talk about time only in the sense of consolidating it, i.e. about filling this one with the work already ready for the time" [11]. So rhythmists see the possibility of rhythmic perception of time and regulation of movements in it, but in fact "rhythmic work can not only use ready given time, but can create something new, according to its own task" [11]. "In fact," explains Muravyov further his thought, "the repetition of some action in time is nothing else, apart from the surrounding, as the resurrection of this action, a system of resurrection acts that transform blind and unreasonable time imposed on us by the universal flow of the natural evolution, in a new, rational time, created by us according to the ideal of our mind" [11].

It is very important to note here that Muravyov spreads portions (acts) of time in two directions-direct and reverse. The flow of external, objective, forced time, he says, is given to me by the perception of the movement of the hand on the watch face. These conditional movements represent the Earth's motion around the sun and daily motion-processes that occur objectively, outside of my control. "Such a nature of these processes, the eternal, in my visibility, movement in one direction, is expressed in the need for calendar dates and associated hours of each day. The calendar and the clock therefore serve as symbols of a certain sequence and events that are beyond my control" [11]. It is clear that it would be impossible to change the course of these events, to reverse them, if the direction of the calendar time indicated by the clock was not probability averaged time (so as it is in the case of quantum physics). Therefore, according to Muravyov, it is necessary to see the possibility of constructing (in a limited sphere) such a calendar and such hours, the movement of which would be not just progressive, but would contain waste back, repetition, and resumption of movements. "In other words, they would have shown cases of treatment and the resumption of time" [11].

The processes of circulation and resumption of time have objective grounds and are manifested not only in human activity. They are responsible for the observed results of the evolution of living nature along the stages of development from the lowest to the highest. But in the social activities of people, man has been given the opportunity, as mentioned above, not only to fix the processes of time reversal, but also to control them, to take into account their productivity. In one of the chapters of Muravyov's book, entitled "Culture as a Mastery of Time," it is said that culture is the result of the creation of time in the sense that every act that changes the world is such a creation. This can be understood if we take into account that the formation of time is accomplished by confirming the duration of any values resisting in this act the corrosive force of time. "These values constitute the values of culture. Their life is always a victory over the allembracing river Heraclitus, and although they, in the end, are carried away by it, each of them, until its destruction, put up some resistance to it, was like a solid sediment in this stream. Such an ability to overcome time, even on a small scale, is obviously an indicator of the potential ability in a much larger caliber to create its own duration "[11].

Muravyov talks about the temporary creation of cultural values. From these positions Heidegger considers the culture of language and speech. The conclusions of both researchers coincide, at least in the sense that in time there is a reverse course due to its dual structure, containing opposite acts. This circumstance underlies the presence of a long-range connection (correlation) between historical events and epochs. 


\section{References}

[1] Levi-Stros K. Strukturnaya antropologia [Lévi Strauss C. Structural anthropology]. Moscow, 1985. P. 188-189.

[2] Khaydegger, Martin. Vremya i Bytiye [Heidegger, Martin. Time and Being]. Moscow: «Respublika», 1993. Pp. 279, 396, 402-403, 403. 397, 312, 269, 171, 400.

[3] Khaydegger, Martin. Tsolikonovskiye seminary (Protokoly Besedy-Pis' ma) [Heidegger, Martin. Zollikonovsky seminars (Protocols Conservations Letters)]. Vilínys: Evropeyskiy gumaniternyy universitet, 2012. Pp. 253, 260, 86, 87.

[4] Heidegger, Martin. Sein und Zeit. Max Niemeyer Verlag, Tübingen, 1967.

[5] Heidegger, Martin. Überlegungen II - VI (Schwarze Hefte 1931- 1938). Vittorio Klostermann GmbH, Frankfurt am Main, 2014. V, S. 78.

[6] Martin Khaidegger sam o sebe v izlozhenii Valtera Bimelya [Martin Heidegger himself as presented by Walter Bimel]. Ural LTD, 1998. P.244.

[7] Kolesov V. V. Drevnyaya Rus': naslediye v slove [Kolesov V. $V$. Ancient Russia: a legacy in the word]. SPb, 2000.
[8] Chertkov A. D. O yazyke pelasgov, naselivshikh Italiyu i sravneniye yego s drevle-slavynskim [Chertkov A. D. On the language of the Pelasgians who inhabited Italy and its comparison with ancient Slavic]. Moscow: Universitet. tipografiya, 1855.

[9] Tolstoi L. N. Sobr. Soch.v 12 tomakh. T.6. [Tolstoi L. N. Sobr. cit. in 12 volums]. Moscow: izd. «Pravda», 1987. Pp. 315, $359,359-360$.

[10] Khomyakov A. S. «Semiramida». Issledovaniye istoricheskikh idey // Soch. v 2 t. T.1 [Khomyakov A. S. «Semiramide». Study of historical ideas]. Moscow, 1994. P. 274.

[11] Muravýov V. N. Ovladeniye vremenem [Muravyov V. N. Mastering time]. Moscow: ROSSPEN, 1998. Pp. 269, 270, 154, 154-155, 108.

[12] Antipenko L. G. Yestestvennonauchnaya otsenka postmodernistskogo podchoda $\mathrm{k}$ lingvistike i litreraturnomu tvorchestvu [Natural Science Assessment of Post-modernist Approach to Linguistics and Literary Creativity]. Yazyk i tekst [Language and text], 2018, t.5, №2. Pp. 14-23. 